\title{
Phylogeny and molecular taxonomy of the Bacillus subtilis species complex and description of Bacillus subtilis subsp. inaquosorum subsp. nov.
}

\author{
Correspondence \\ Alejandro P. Rooney \\ alejandro.rooney@ars.usda.gov
}

\author{
Alejandro P. Rooney, ${ }^{1}$ Neil P. J. Price, ${ }^{2}$ Christopher Ehrhardt, ${ }^{3}$ \\ James L. Swezey ${ }^{1}$ and Jason D. Bannan ${ }^{4}$
}
${ }^{1}$ Microbial Genomics and Bioprocessing Research Unit, National Center for Agricultural Utilization Research, Agricultural Research Service, US Department of Agriculture, Peoria, IL 61604, USA
${ }^{2}$ Bioproducts and Biocatalysis Research Unit, National Center for Agricultural Utilization Research, Agricultural Research Service, US Department of Agriculture, Peoria, IL 61604, USA
${ }^{3}$ Counterterrorism and Forensic Science Research Unit, Federal Bureau of Investigation Academy, Quantico, VA 22135, USA
${ }^{4}$ Chemical-Biological Sciences Unit, Laboratory Division, Federal Bureau of Investigation, Quantico, VA 22135, USA

The Bacillus subtilis species complex is a tight assemblage of closely related species. For many years, it has been recognized that these species cannot be differentiated on the basis of phenotypic characteristics. Recently, it has been shown that phylogenetic analysis of the $16 \mathrm{~S}$ rRNA gene also fails to differentiate species within the complex due to the highly conserved nature of the gene, yet DNA-DNA hybridization values fall well below $70 \%$ for the same species comparisons. As a complementary approach, we propose that phylogenetic analysis of multiple protein-coding loci can be used as a means to detect and differentiate novel Bacillus taxa. Indeed, our phylogenetic analyses revealed the existence of a previously unknown group of strains closely related to, but distinct from, Bacillus subtilis subsp. spizizenii. Results of matrix-assisted laser desorption ionization-time of flight mass spectrometry analyses revealed that the group produces a novel surfactin-like lipopeptide with mass $\mathrm{m} / \mathrm{z} 1120.8$ that is not produced by the other currently recognized subspecies. In addition, the group displayed differences in the total cellular content of the fatty acids $\mathrm{C}_{16: 0}$ and iso- $\mathrm{C}_{17: 1} \omega 10 \mathrm{c}$ that distinguish it from the closely related $B$. subtilis subsp. spizizenii. Consequently, the correlation of these novel phenotypic traits with the phylogenetic distinctiveness of this previously unknown subspecies group showed that phylogenetic analysis of multiple protein-coding loci can be used as a means to detect and differentiate novel Bacillus taxa. Therefore, we propose that this new group should be recognized as representing a novel taxon, Bacillus subtilis subsp. inaquosorum subsp. nov., with the type strain NRRL B-23052 $2^{\top}\left(=\right.$ KCTC $13429^{\top}=$ BGSC $\left.3 A 28^{\top}\right)$.
Abbreviations: FAME, fatty acid methyl ester; MALDI-TOF MS, matrixassisted laser desorption ionization-time of flight mass spectrometry; NJ, neighbour-joining; ML, maximum-likelihood; MP, maximumparsimony.

The GenBank/EMBL/DDBJ accession numbers for the sequences generated in this study are EU138452-EU138865.

A maximum-parsimony cladogram of the Bacillus subtilis species complex and tables showing the mean values of synonymous and non-synonymous substitutions per site among protein-coding genes and the geographical origins, isolation substrates and maximum growth temperatures for $B$. subtilis subsp. inaquosorum subsp. nov., $B$. subtilis subsp. spizizenii and $B$. subtilis subsp. subtilis are available as supplementary material with the online version of this paper.

\section{INTRODUCTION}

The genus Bacillus is composed of rod-shaped, endosporeforming bacteria that are members of the phylum Firmicutes. Owing largely to the fact that they are common inhabitants of soil and aquatic sediment, species within the genus are widespread in nature and are found in virtually every environment. While their main roles appear to involve carbon and nitrogen cycling, some species are wellknown human and livestock pathogens (e.g. Bacillus anthracis and Bacillus cereus) and insect pathogens (e.g. Bacillus thuringiensis). However, the overwhelming majority of Bacillus species are non-pathogenic. Because of this fact, many have been exploited for biotechnological and 
industrial applications (Hou et al., 2005; Ruiz-García et al., 2005a, b; Bischoff et al., 2006; Price et al., 2007). One such species, which is also one of the more commonly encountered ones in the environment, is Bacillus subtilis (Cohn, 1872).

Over the last 20 years, several species very closely related to $B$. subtilis have been described. These species include Bacillus amyloliquefaciens (Priest et al., 1987), Bacillus atrophaeus (Nakamura, 1989), Bacillus axarquiensis (RuizGarcía et al., 2005b; but see Wang et al., 2007), Bacillus malacitensis (Ruiz-García et al., 2005b; but see Wang et al., 2007), Bacillus mojavensis (Roberts et al., 1994), Bacillus sonorensis (Palmisano et al., 2001), Bacillus tequilensis (Gatson et al., 2006), Bacillus vallismortis (Roberts et al., 1996) and Bacillus velezensis (Ruiz-García et al., 2005a; but see Wang et al., 2008). Interestingly, most of the above species share a remarkably high level of $16 \mathrm{~S}$ rRNA gene sequence similarity to B. subtilis (often $99 \%$ or greater) even though DNA-DNA hybridization values with the latter fall below $70 \%$. Moreover, very few phenotypic or biochemical characteristics can be found that differentiate these species from B. subtilis. This high degree of phenotypic and biochemical similarity prompted Gordon et al. (1973) to characterize species closely related to $B$. subtilis as members of the 'subtilis-group' or 'subtilisspectrum'. Herein, we refer to this assemblage as the $B$. subtilis species complex.

The inability of phenotypic, biochemical and16S rRNA gene phylogenetic analysis to identify species within the $B$. subtilis species complex and to resolve phylogenetic relationships among those species is an important problem to resolve for those interested in Bacillus systematics. Most importantly, it raises the question that, if one wishes to apply modern principles of phylogenetic systematics, where and how does one 'draw the line' in the attempt to delineate a novel species of Bacillus. Recently, it has been suggested that the use of multilocus sequence analysis should be investigated as a means to detect and define novel species of bacteria (Stackebrandt et al., 2002; Gevers et al., 2005). The purpose of this study was to investigate the use of multilocus phylogenetic analysis as a tool to detect novel taxa within the B. subtilis species complex, which has become a model system for the study of bacterial speciation (Cohan, 2001, 2002, 2006; Perry et al., 2007).

\section{METHODS}

Strains and phenotypic analyses. All strains used in this study are permanently archived within the USA Department of Agriculture Agricultural Research Service (ARS) Culture Collection (commonly known by the acronym NRRL; <http://nrrl.ncaur.usda.gov $>$ ). Experiments involving temperature range for growth $\left(4-58{ }^{\circ} \mathrm{C}\right)$, salt concentration tolerance $(5-15 \%, w / v)$ and anaerobic growth were conducted using tryptone-glucose-yeast extract (TGY) media $(5.0 \mathrm{~g}$ tryptone, 5.0 g yeast extract, 1.0 g glucose, $1.0 \mathrm{~g} \mathrm{~K}_{2} \mathrm{HPO}_{4}$, $11 \mathrm{ddH}_{2} 0$; $\mathrm{pH}$ 7.0). All other phenotypic analyses were conducted according to Gordon et al. (1973). Tests for the production of acid from various carbohydrates were conducted using the API CH 50 system
(bioMérieux), following the manufacturer's suggested protocol. Lipopeptide biomarker profiles were determined by using matrixassisted laser desorption ionization-time of flight mass spectrometry (MALDI-TOF MS) using the method of Price et al. (2007) as follows. MALDI-TOF mass spectra were acquired on a Bruker-Daltonic Omniflex instrument operating in reflecton mode. Ion source 1 was set to $19.0 \mathrm{kV}$ and source 2 to $14.0 \mathrm{kV}$, with lens and reflector voltages of 9.20 and $20.00 \mathrm{kV}$, respectively. Aqueous samples were cocrystallized with 2,5-dihydrobenzoic acid matrix $\left(10 \mathrm{mg} \mathrm{ml}^{-1}\right.$ in acetonitrile) on a Bruker-Daltonics 49-place target. The laser output was at $337.1 \mathrm{~nm}$, typically at $60 \%$ of 150 í maximum output, and 80 shots were accumulated. A 200 ns pulsed ion extraction was used with matrix suppression up to $200 \mathrm{Da}$. The instrument was calibrated externally on a dp series of malto-oligosaccharides.

Fatty acid methyl ester (FAME) analyses were conducted as follows. Lyophilized cultures maintained by the ARS Culture Collection were rehydrated in $3 \mathrm{ml}$ trypticase soy broth (Difco) and incubated for $12 \mathrm{~h}$ at $30{ }^{\circ} \mathrm{C}$ with shaking at 200 r.p.m. Small $(100 \mu \mathrm{l})$ aliquots of liquid culture were then spread onto trypticase soy agar (Difco) plates and incubated for $24 \mathrm{~h}$ at $30{ }^{\circ} \mathrm{C}$. Following incubation, bacterial colonies (approx. $3 \mathrm{mg}$ wet weight) were transferred to $2 \mathrm{ml}$ screw cap vials and prepared for fatty acid extraction. Fatty acid extraction and analysis were performed according to the Instant FAME sample preparation method (MIDI, Inc.). Gas chromatography was performed on a Agilent $6890 \mathrm{~N}$ analyzer using calibration standards (\#1300-AA; MIDI, Inc.). The Sherlock Microbial Identification (MIDI, Inc.) software was used to assign GC peaks to individual fatty acid structures.

Gene sequence data collection. All strains were grown in $5 \mathrm{ml}$ TGY broth and incubated aerobically at $28{ }^{\circ} \mathrm{C}$ for $24 \mathrm{~h}$. DNA was extracted from each strain using a MasterPure Gram-positive DNA purification kit (Epicentre Biotechnologies) following the manufacturer's protocol. For each strain, we obtained partial nucleotide sequences for the following genes: gyrase subunit A (gyrA), RNA polymerase subunit B $(r p o B)$, phosphoribosylaminoimidazolecarboxamide formyltransferase (purH), DNA polymerase III subunit alpha (polC), $60 \mathrm{kDa}$ heat-shock protein groEL (groEL) and 16S rRNA.

PCR amplifications were performed with 1 unit AmpliTaq DNA polymerase (Invitrogen Life Technologies), $2.5 \mathrm{mM} \mathrm{MgCl}_{2}, 200 \mu \mathrm{M}$ dNTPs, $1.0 \mu \mathrm{M}$ each of forward and reverse oligonucleotide primers, $1 \times$ reaction buffer and 50-100 ng template DNA. The universal oligonucleotide primers 27f (Lane, 1991) and 1387r (Marchesi et al., 1998) were used to amplify and sequence the $16 \mathrm{~S}$ rRNA gene using an annealing temperature of $54{ }^{\circ} \mathrm{C}$. The oligonucleotide primer sequences for all other genes are listed in Table 1. All PCRs were performed for 35 cycles, each consisting of a $30 \mathrm{~s}$ denaturation step at $94{ }^{\circ} \mathrm{C}$, a $30 \mathrm{~s}$ annealing step between 45 and $55{ }^{\circ} \mathrm{C}$ (all amplifications were done using as high an annealing temperature as possible, with subsequent lowering in $2{ }^{\circ} \mathrm{C}$ increments until amplification occurred), and a 1 min extension step at $72{ }^{\circ} \mathrm{C}$. Amplification products were purified using Montage PCR Cleanup Filter Plates (Millipore). Sequencing reactions were conducted using the ABI BigDye version 3.0 sequencing kit (Applied Biosystems) following the manufacturer's suggested protocol but at one-fourth the recommended volume. Reaction products were purified via ethanol precipitation and run on an ABI3730 genetic analyzer (Applied Biosystems). DNA sequences were edited visually using Sequencher version 4.1.2 (Gene Codes) and aligned manually. The nucleotide sequence alignment of concatenated genes consisted of $5550 \mathrm{bp}$ (928 bp from gyrA, 964 bp from rpoB, 875 bp from $p u r H, 777$ bp from polC, $835 \mathrm{bp}$ from groEL and $1171 \mathrm{bp}$ from $16 \mathrm{~S}$ rRNA). We also included homologous nucleotide sequence data from the sequenced genomes of B. subtilis 168, Bacillus licheniformis DSM $13^{\mathrm{T}}$, and $B$. cereus ATCC $14579^{\mathrm{T}}$ in the alignment. With the completed genome 
Table 1. Primers used to amplify protein-coding loci

Primers are numbered according to the first nucleotide in their respective genes as per the $B$. subtilis 168 published genome sequence (GenBank accession no. NC_000964).

\begin{tabular}{|c|c|}
\hline Primer name & Sequence $\left(5^{\prime}-3^{\prime}\right)$ \\
\hline$g y r A-42 \mathrm{f}^{*}$ & CAGTCAGGAAATGCGTACGTCCTT \\
\hline gyrA-1066r ${ }^{*}$ & CAAGGTAATGCTCCAGGCATTGCT \\
\hline$r p o B-2292 \mathrm{f}$ & GACGTGGGATGGCTACAACT \\
\hline rpoB-3354r & ATTGTCGCCTTTAACGATGG \\
\hline purH-70f & ACAGAGCTTGGCGTTGAAGT \\
\hline purH-1013r & GCTTCTTGGCTGAATGAAGG \\
\hline polC-1505f & TTGTCGCTCAYAATGCAAGC \\
\hline polC-2337r & YTCAAGCATTTCRTCTGTCG \\
\hline groEL-550f & GAGCTTGAAGTKGTTGAAGG \\
\hline groEL-1497r & TGAGCGTGTWACTTTTGTWG \\
\hline
\end{tabular}

${ }^{\star}$ The gyrA primer sequences were taken from Chun \& Bae (2000); positional numbering was added in order to conform to the system in place for the above primers as well as the 16S rRNA gene primers.

data, the total number of strains analysed was 72. All sequences generated in this study have been deposited in GenBank and are retrievable by typing in their NRRL accession numbers in the Entrez retrieval system (http://www.ncbi.nlm.nih.gov/sites/entrez).

\begin{abstract}
Phylogenetic analyses. Phylogenetic analyses of gene sequence data were conducted using neighbour-joining (NJ) (Saitou \& Nei, 1987), maximum-likelihood (ML) and maximum-parsimony (MP) methods. The computer program MEGA 3.1 (Kumar et al., 2004) was used to reconstruct NJ trees from Tamura \& Nei (1993) gamma distances. The gamma shape parameter used was 0.223 , which was estimated using the program DAMBE version 4.5.40 (Xia \& Xie, 2001). The reliability of internal branches was assessed from 1500 bootstrap pseudoreplicates. The program DNAPARS in the software package PHYLIP (Felsenstein, 2006) was used to conduct MP analyses using 100 random-addition replicates. Gaps were considered an additional character state in the MP analysis. The reliability of internal branches was assessed from 1000 bootstrap pseudoreplicates. The program GARLI version 0.951 (Zwickl, 2006) was used to conduct ML analyses. A general time reversible model with gamma-distributed among-site rate variation and a proportion of invariant sites was used. The analysis was run for 5 million generations, with a threshold value of 10000 for the termination condition. The reliability of internal branches was assessed from 500 bootstrap pseudoreplicates.
\end{abstract}

\section{RESULTS AND DISCUSSION}

The results from NJ, MP, ML and analyses of concatenated gene sequences are shown in Fig. 1 and Supplementary Fig. S1 (available in IJSEM Online). These figures represent the phylogeny reconstructed from the concatenated sequence of all five protein-coding loci and the $16 \mathrm{~S}$ rRNA gene. The 16S rRNA gene is highly conserved and there is no phylogenetic information present in this gene for resolving closely related $B$. subtilis complex members (Roberts et al., 1994, 1996; Chun \& Bae, 2000; Palmisano et al., 2001; Ruiz-García et al., 2005a, b; Gatson et al., 2006). However, there is some information present that provides resolution regarding the deeper divergences in the complex (Ash et al., 1991). Therefore, we included this gene in the concatenation. With respect to the proteincoding loci, the gyrA and groEL genes show some low levels of discordance in comparison to the other genes with respect to the phylogenetic placement of four strains of $B$. subtilis. The gyrA and groEL genes represent the fastest- and slowest-evolving loci, respectively, in our dataset as judged by levels of synonymous $\left(d_{S}\right)$ and non-synonymous $\left(d_{\mathrm{N}}\right)$ site divergence (Supplementary Table S1, available in IJSEM Online). The phylogenetic discordance observed is discussed later in the text as it pertains to relationships among strains of B. subtilis.

Nevertheless, because the individual gene phylogenies are congruent to one another and to the concatenated gene phylogeny, we discuss relationships within the B. subtilis species complex in reference to the concatenated phylogenies only (Fig. 1 and Supplementary Fig. S1). We addressed the relationships from the most basal member of the complex to the most derived. Thus, we began with Bacillus pumilus. This species was found at the base of the $B$. subtilis species complex phylogeny. Interestingly, Gordon et al. (1973) speculated that it might one day be considered a 'variety of $B$. subtilis rather than a separate species' once more data were collected on a large number of $B$. pumilus strains. However, our results clearly indicate that $B$. pumilus forms a clade distinct from B. subtilis (Fig. 1 and Supplementary Fig. S1).

The next group of species is represented by $B$. licheniformis and $B$. sonorensis. These two species are reported to be differentiable on the basis of salt tolerance (Palmisano et al., 2001). However, reliance on phenotypic characteristics for differentiating species of the B. subtilis species complex should be avoided, as certain traits that currently might be considered reliable might prove otherwise once more strains have been examined. For instance, it has been presumed for quite some time that $B$. licheniformis can be separated from $B$. subtilis on the basis of facultative anaerobic growth as well as growth at $56{ }^{\circ} \mathrm{C}$ (Kundrat, 1963; Gordon et al., 1973). However, many strains of $B$. subtilis are capable of anaerobic growth in the presence of glucose (Rooney et al., 2005) and a number of strains are capable of growth at or above $56{ }^{\circ} \mathrm{C}$ (Supplementary Table S2, available in IJSEM Online), which reinforces the observation that species within the B. subtilis complex cannot be reliably differentiated on the basis of morphological, physiological, biochemical or other phenotypic properties.

The species B. amyloliquefaciens is the next to branch off from the remainder of the B. subtilis species complex (Fig. 1 and Supplementary Fig. S1). B. amyloliquefaciens is an industrially important species that is used for a number of applications, most notably for the production of $\alpha$-amylase. Recently, Ruiz-García et al. (2005a) described a group of strains closely related to $B$. amyloliquefaciens as representing a novel species, B. velezensis. The latter is also 


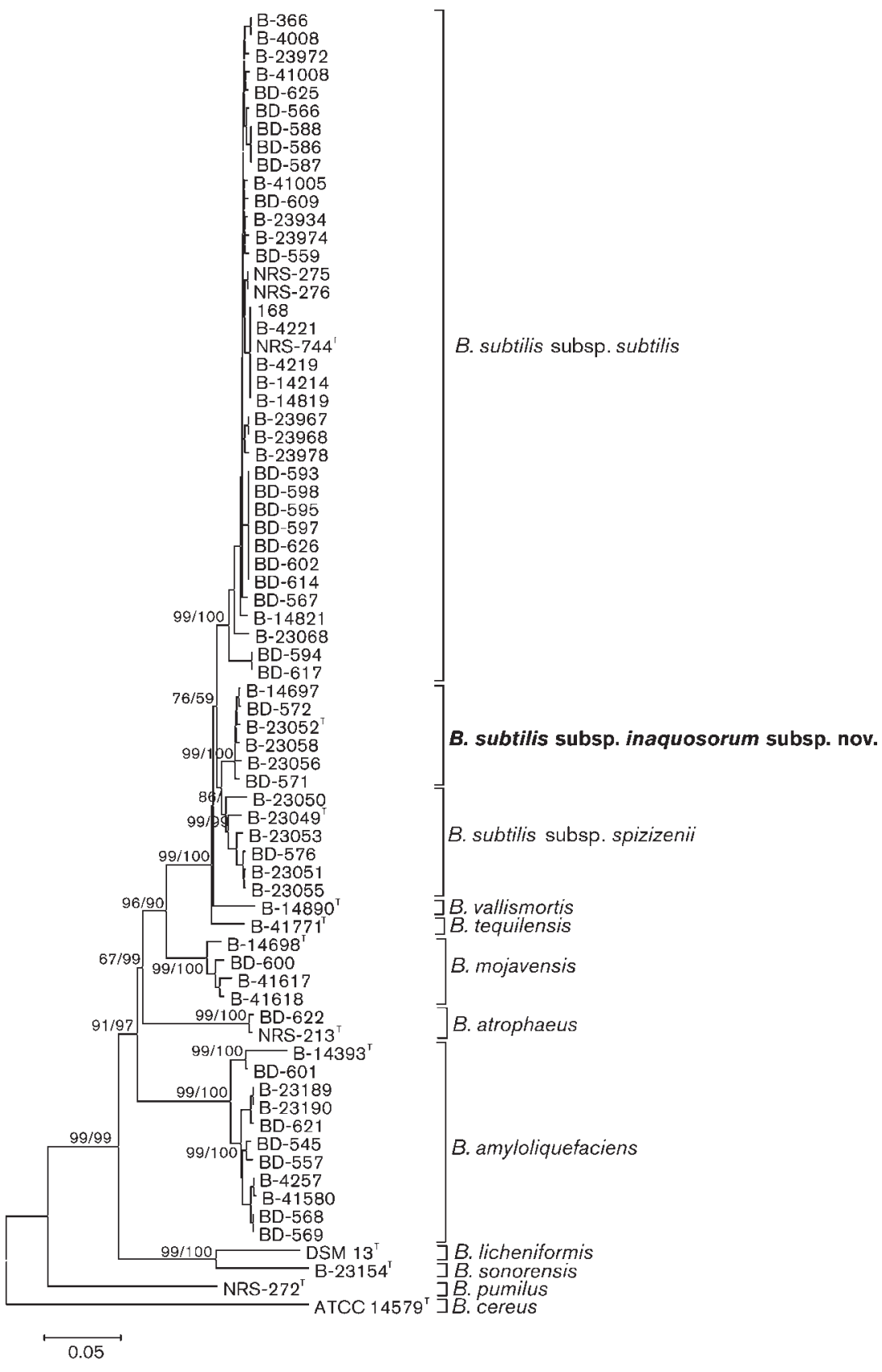

Fig. 1. NJ phylogeny of the $B$. subtilis species complex. Numbers at branch points indicate bootstrap percentages from both NJ (before the slash ' $/$ ') and ML (after the slash ' $/$ ') analyses. Only values greater than $50 \%$ are shown. Because the ML tree was very similar to the $\mathrm{NJ}$ tree, only the latter is shown here. $B$. cereus was used as the outgroup taxon to root the tree. potentially valuable to a number of industries, as certain strains were shown to produce high levels of surfactins (Ruiz-García et al., 2005a). However, Wang et al. (2008) reclassified $B$. velezensis as a later heterotypic synonym of $B$. amyloliquefaciens on the basis of DNA-DNA hybridization data. In our study, B. amyloliquefaciens and B. velezensis $\left(\right.$ NRRL B-41580 ${ }^{\mathrm{T}}$ ) were found to be very closely related and could not be reliably differentiated from one another or other B. subtilis complex species without the use of gene sequence data (Fig. 1 and Supplementary Fig. S1).

The next species to consider in the B. subtilis species complex phylogeny are B. atrophaeus and B. mojavensis. As with the previously discussed two species, certain $B$. atrophaeus strains are potentially useful for industrial applications (Schmidt et al., 1979). Strains of B. atrophaeus typically produce dark brown to black pigments but are otherwise indistinguishable from $B$. subtilis and related species on the basis of other phenotypic, morphological, physiological or biochemical characteristics. B. mojavensis is a desert-adapted species and is similarly difficult to distinguish from B. subtilis, except for minor differences in cell-wall fatty acid content (Roberts et al., 1994). Two species described by Ruiz-García et al. (2005a), B. malacitensis and $B$. axarquiensis, were found to be very closely related to B. mojavensis, but Wang et al. (2007) 
reclassified these two species as later heterotypic synonyms of B. mojavensis. Similarly, the results of our phylogenetic analyses (Fig. 1 and Supplementary Fig. S1) show that strains NRRL B- $41617^{\mathrm{T}}$ and NRRL B-41618 ${ }^{\mathrm{T}}$ (the type strains of B. axarquiensis and B. malacitensis, respectively) cluster with the $B$. mojavensis type strain as well as another reference strain of that species.

The last group consists of B. subtilis, B. tequilensis and B. vallismortis. In Fig. 1 and Supplementary Fig. S1, three clades of $B$. subtilis can be recognized: (i) a clade corresponding to B. subtilis subsp. subtilis (Nakamura et al., 1999); (ii) a clade corresponding to B. subtilis subsp. spizizenii (Nakamura et al., 1999); and (iii) a third clade that we propose to be recognized as representing a novel subspecies, Bacillus subtilis subsp. inaquosorum subsp. nov. Each of the three groups was supported with high bootstrap values (99-100\%; Fig. 1 and Supplementary Fig. S1). However, the bootstrap support for a monophyletic B. subtilis was weak (52-77\%). In addition, the results of the MP analysis (Supplementary Fig. S1, in IJSEM Online) suggest that B. subtilis, as it is currently recognized (Nakamura et al., 1999), is paraphyletic. In this case, B. subtilis subsp. spizizenii and the proposed subspecies B. subtilis subsp. inaquosorum subsp. nov. cluster apart from B. subtilis subsp. subtilis. This result needs further evaluation in follow-up studies, although it could be a simple case of systematic error in the MP tree. Regardless, the results of our analyses indicate that there is a third phylogenetic group of $B$. subtilis strains that cluster apart from the two currently recognized subspecies and that this group is closely related to B. subtilis subsp. spizizenii. Thus, to determine whether or not there were any phenotypic characteristics that could distinguish this new group from $B$. subtilis subsp. spizizenii, we conducted MALDI-TOF MS and FAME analyses.

MALDI-TOF MS biomarker profiles over the 300-1200 mass unit range were obtained. Abundant lipopeptide MS ions were observed in four subdivided mass ranges: (1) $\mathrm{m} / \mathrm{z}$ 520-600, (2) $\mathrm{m} / \mathrm{z} 710-770$, (3) $\mathrm{m} / \mathrm{z} 880-970$ and (4) $\mathrm{m} / \mathrm{z}$ 1050-1150. In mass range 1, ubiquitous lipopeptide ions were observed at $\mathrm{m} / z 562.8$ and 590.8 . In mass range $2, \mathrm{~m} / \mathrm{z}$ 710.7 and 728.7 were present for ten strains, but were not species-specific. Mass range 3 contained four ions, $\mathrm{m} / \mathrm{z}$ 886.9, 901.0, 914.0 and 930.9, previously assigned as probable kurstakins (Price et al., 2007). These were generally present except for B. vallismortis NRRL B$14890^{\mathrm{T}}$. An ion $(\mathrm{m} / z$ 1057.8) in the high mass range was observed for all strains tested and is assigned as the $[\mathrm{M}+\mathrm{Na}]^{+}$molecular adduct ion for the surfactin lipopeptide Leu/Ile, C15 (Price et al., 2007). The B. subtilis subsp. inaquosorum subsp. nov. strains were characterized by an additional major ion at $\mathrm{m} / z 1120.8$ and a smaller ion at $\mathrm{m} / \mathrm{z}$ 1106.8 (Fig. 2). These were observed for all B. subtilis subsp. inaquosorum subsp. nov. strains tested and often were the most intense ions observed. Similar markers $(\mathrm{m} / \mathrm{z}$ 1121.8 and 1105.8) were seen for B. tequilensis NRRL B$41771^{\mathrm{T}}$, but spectral overlay showed these to be different
(Fig. 2). The smaller ion $(\mathrm{m} / z$ 1106.8) was also present in three B. subtilis subsp. spizizenii strains (NRRL B-23049 ${ }^{\mathrm{T}}$, B-23055 and BD-576) but not the larger ion $(\mathrm{m} / z$ 1120.8), which was only observed among B. subtilis subsp. inaqusorum subsp. nov. strains. Hence, the biomarker at $\mathrm{m} / \mathrm{z} 1120.8$ is unique to $B$. subtilis subsp. inaquosorum subsp. nov and can be used in addition to gene sequence analysis to differentiate these strains from other B. subtilis subspecies.

The results of the FAME analysis (Table 2) revealed that there were differences between B. subtilis subsp. inaquosorum subsp. nov and $B$. subtilis subsp. spizizenii with respect to total cellular content of the fatty acids $\mathrm{C}_{16: 0}$ and iso- $\mathrm{C}_{17: 1} \omega 10 c$, which are minor components of the total complement. The values for these fatty acids are highlighted in bold in Table 2, which also includes data for the type strains of B. subtilis subsp. subtilis, B. tequilensis and $B$. vallismortis for comparative purposes. Under the growth conditions used, it was found that B. subtilis subsp. inaquosorum subsp. nov made more $\mathrm{C}_{16: 0}$ than $B$. subtilis subsp. spizizenii, whereas $B$. subtilis subsp. spizizenii made more iso- $\mathrm{C}_{17: 1} \omega 10 c$ than $B$. subtilis subsp. inaquosorum subsp. nov. In addition, B. subtilis subsp. inaquosorum strains made more $\mathrm{C}_{16: 0}$ than iso- $\mathrm{C}_{17: 1} \omega 10 c$, whereas the amounts were much closer in the case of the B. subtilis subsp. spizizenii strains.

Interestingly, strains from each of the three aforementioned subspecies clades were isolated from the same samples of desert soils from various locations around the world (Supplementary Table S2, in IJSEM Online) and in each case the strains display a pattern of reciprocal monophyly, in which strains from one subspecies cluster with other strains of the same subspecies regardless of where they originate geographically. Thus, for example, strains of all three $B$. subtilis subspecies that were isolated from the same Mojave Desert soil sample (Supplementary Table S2) do not cluster together; instead they cluster with other members of their respective subspecies (Fig. 1 and Supplementary Fig. S1). This pattern of reciprocal monophyly indicates that each subspecies is on its own evolutionary trajectory (Dykhuizen \& Green, 1991; Avise, 2000; Cohan 2001, 2002) and also suggests that each subspecies fills an ecological niche distinct from the other subspecies (Cohan, 2001, 2002, 2006; Perry et al., 2007; Koeppel et al., 2008). This ecological distinction is most probably the explanation for the patterns of reciprocal monophyly and the production of unique lipopetides and differences in total cellular fatty acid components. What is most important, however, is that groups are phylogenetically distinct and have embarked on separate evolutionary paths. Moreover, as we were able to correlate phylogenetic distinctiveness with novel phenotypic traits, our study shows that phylogenetic analysis of multiple proteincoding loci can be used to detect novel bacterial taxa, even those that are very closely related such as subspecies of $B$. subtilis. In that regard, we propose that the third subspecies clade of B. subtilis identified in this study should 
(a)

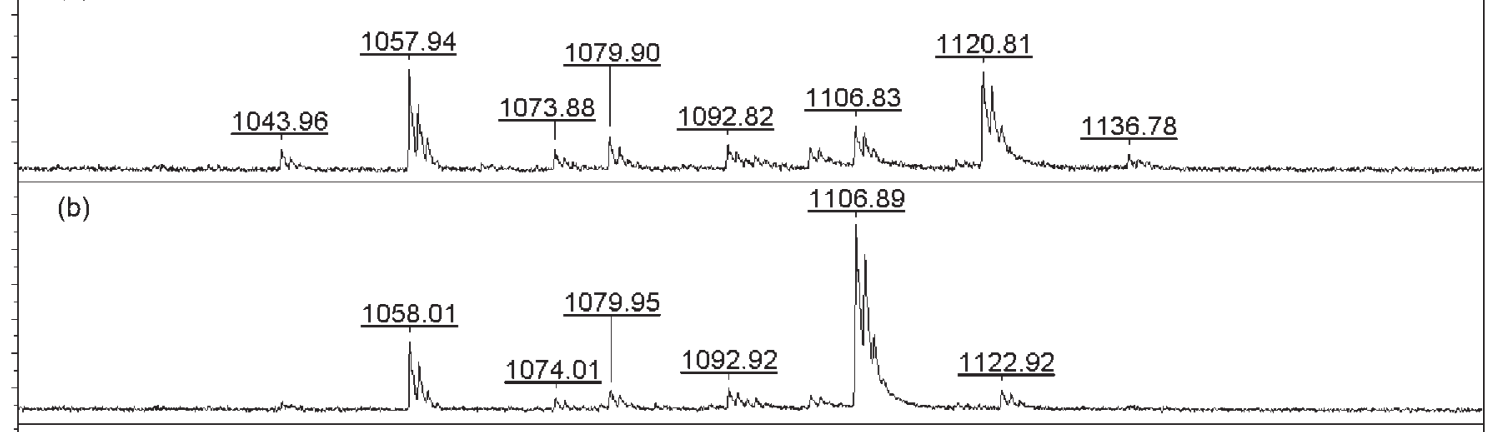

(c)

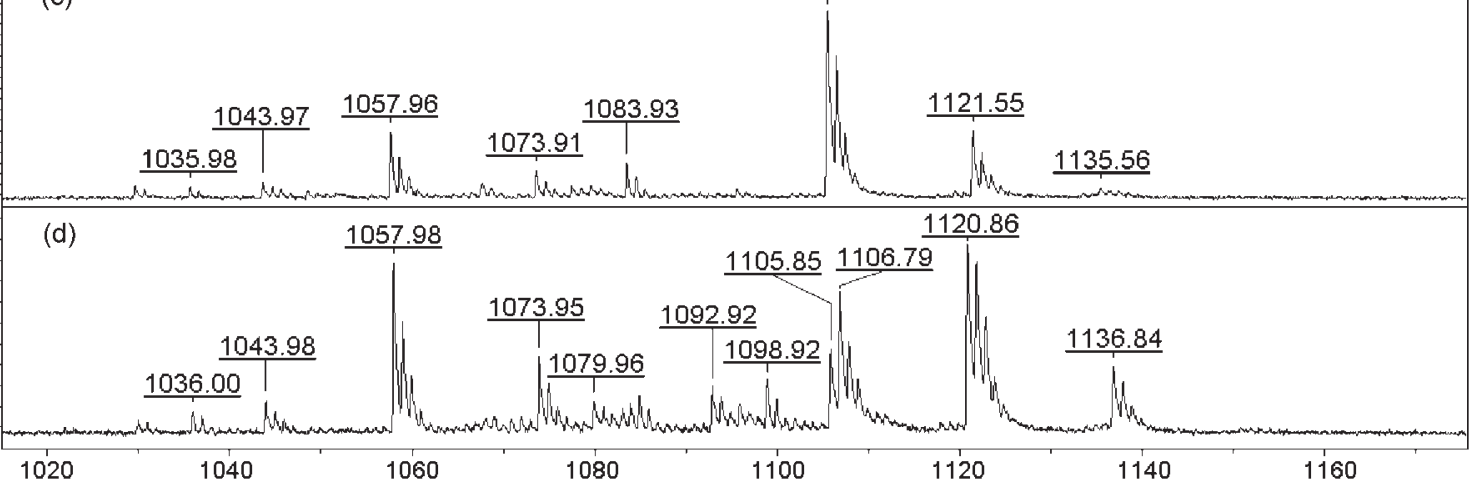

Fig. 2. Representative MALDI-TOF MS ion profiles ( $m / z$ 1020-1160) of (a) B. subtilis subsp. inaquosorum subsp. nov.

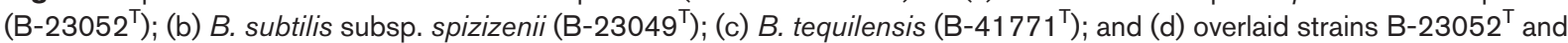
$\mathrm{B}-41771^{\top}$. Of note are surfactin $[\mathrm{M}+\mathrm{Na}]^{+}$ions $(\mathrm{m} / \mathrm{z} 1044$ and 1058$)$ and a $B$. subtilis subsp. inaquosorum subsp. nov.-specific ion, $\mathrm{m} / \mathrm{z} 1120.8$.

Table 2. Cellular fatty acid contents of type and reference strains of $B$. subtilis subsp. inaquosorum subsp. nov. and $B$. subtilis subsp. spizizenii, as well as the type strains of $B$. subtilis subsp. subtilis, B. tequilensis and B. vallismortis

NRRL strain numbers: 1, B-23052 ; 2, B-23056; 3, B-23058; 4, B-14697; 5, BD-571; 6, BD-572; 7, B-23049 ${ }^{\mathrm{T}}$; 8, B-23050; 9, B-23051; 10, B-23055; 11, BD-576. Values are percentages of the total.

\begin{tabular}{|c|c|c|c|c|c|c|c|c|c|c|c|c|c|c|}
\hline \multirow[t]{2}{*}{ Fatty acid } & \multicolumn{6}{|c|}{ B. subtilis subsp. inaquosorum } & \multicolumn{5}{|c|}{ B. subtilis subsp. spizizenii } & \multirow{2}{*}{$\begin{array}{c}\text { B. subtilis } \\
\text { subsp. subtilis } \\
{\text { NRS- } 744^{\mathrm{T}}}^{\text {Not }}\end{array}$} & \multirow{2}{*}{$\begin{array}{c}\text { B. } \\
\text { tequilensis } \\
\text { B-41771 }^{\mathrm{T}}\end{array}$} & \multirow{2}{*}{$\begin{array}{c}\text { B. } \\
\text { vallismortis } \\
{\text { B- } 14890^{\mathrm{T}}}^{\text {Th }}\end{array}$} \\
\hline & 1 & 2 & 3 & 4 & 5 & 6 & 7 & 8 & 9 & 10 & 11 & & & \\
\hline iso- $\mathrm{C}_{13: 0}$ & 0.1 & 0.0 & 0.2 & 0.1 & 0.2 & 0.1 & 0.0 & 0.0 & 0.0 & 0.0 & 0.1 & 0.1 & 0.1 & 5.9 \\
\hline iso- $\mathrm{C}_{14: 0}$ & 0.6 & 1.2 & 0.9 & 0.9 & 0.7 & 0.7 & 0.6 & 0.6 & 0.6 & 0.6 & 0.6 & 0.8 & 0.7 & 6.2 \\
\hline $\mathrm{C}_{14: 0}$ & 0.2 & 0.3 & 0.3 & 0.2 & 0.2 & 0.2 & 0.1 & 0.0 & 0.1 & 0.0 & 0.1 & 0.2 & 0.2 & 3.3 \\
\hline iso- $\mathrm{C}_{15: 0}$ & 22.6 & 20.3 & 26.4 & 24.6 & 28.4 & 23.8 & 17.4 & 16.0 & 19.2 & 21.6 & 28.0 & 19.4 & 18.8 & 34.6 \\
\hline anteiso- $\mathrm{C}_{15: 0}$ & 39.2 & 42.1 & 39.7 & 37.5 & 39.5 & 40.4 & 39.5 & 39.5 & 41.0 & 39.2 & 36.8 & 38.2 & 47.1 & 3.7 \\
\hline $\mathrm{C}_{16: 1} \omega 7 c$ & 0.2 & 0.2 & 0.3 & 0.3 & 0.2 & 0.4 & 0.5 & 0.3 & 0.4 & 0.4 & 0.3 & 1.2 & 0.4 & 0.6 \\
\hline $\mathrm{C}_{16: 1} \omega 11 c$ & 0.4 & 0.4 & 0.6 & 0.6 & 0.3 & 0.6 & 0.8 & 0.5 & 0.7 & 0.5 & 0.5 & 1.6 & 1.1 & 0.1 \\
\hline iso- $\mathrm{C}_{16: 0}$ & 2.5 & 5.0 & 3.1 & 3.4 & 2.4 & 2.5 & 2.6 & 3.0 & 2.6 & 2.6 & 1.9 & 2.5 & 2.4 & 7.0 \\
\hline$C_{16: 0}$ & 2.9 & 3.4 & 2.9 & 2.7 & 2.6 & 2.4 & 1.9 & 1.8 & 1.9 & 1.5 & 1.6 & 1.9 & 2.1 & 2.8 \\
\hline iso- $\mathrm{C}_{17: 1} \omega 10 c$ & 1.0 & 0.4 & 0.8 & 0.9 & 0.6 & 1.3 & 2.1 & 1.3 & 1.7 & 1.8 & 1.7 & 5.2 & 1.4 & 1.4 \\
\hline iso- $\mathrm{C}_{17: 1} \omega 5 c$ & 0.0 & 0.0 & 0.0 & 0.0 & 0.0 & 0.0 & 0.0 & 0.0 & 0.0 & 0.0 & 0.0 & 0.0 & 0.0 & 5.1 \\
\hline iso- $\mathrm{C}_{17: 0}$ & 14.3 & 10.8 & 12.1 & 15.1 & 12.6 & 12.5 & 15.3 & 15.8 & 13.4 & 15.1 & 15.0 & 11.2 & 7.0 & 8.9 \\
\hline anteiso- $\mathrm{C}_{17: 0}$ & 14.8 & 15.4 & 12.1 & 12.5 & 11.7 & 14.1 & 17.0 & 19.5 & 17.0 & 15.0 & 12.2 & 12.1 & 17.0 & 0.8 \\
\hline iso- $\mathrm{C}_{19: 0}$ & 0.0 & 0.0 & 0.0 & 0.1 & 0.0 & 0.0 & 0.2 & 0.0 & 0.0 & 0.0 & 0.0 & 0.6 & 0.0 & 1.2 \\
\hline
\end{tabular}


be formally recognized as Bacillus subtilis subsp. inaquosorum subsp. nov.

\section{Description of Bacillus subtilis subsp. inaquosorum subsp. nov.}

Bacillus subtilis subsp. inaquosorum [in.a.quo.so'rum. L. adj. inaquosus poor of water, L. gen. pl. n. (solium) inaquosorum from (soils) poor of water (desert soils) from which this organism was isolated].

Vegetative cells are rods that measure $0.5 \times 3 \mu \mathrm{m}$ and occur either singly or in chains. Motile. Cylindrical spores form centrally or paracentrally in non-swollen sporangia. Facultatively anaerobic on TGY agar or broth. Catalasepositive. Grows at $15-55{ }^{\circ} \mathrm{C}$, with optimum growth at $28-30{ }^{\circ} \mathrm{C}$. Growth in $10 \%(\mathrm{w} / \mathrm{v}) \mathrm{NaCl}$ occurs after $72 \mathrm{~h}$. Growth in the presence of $0.001 \%(\mathrm{w} / \mathrm{v})$ lysozyme is variable. Produces acetyl-methylcarbinol (VogesProskauer test) at pH 5.5-5.7. Hydrolyses starch and casein; reduces nitrate to nitrite. Citrate is utilized. Acid is produced from amygdalin, glycogen, melibiose, Dglucose, cellobiose, D-mannitol, D-sorbitol and aesculin ferric citrate, as determined using the API $\mathrm{CH} 50$ system. Produces a surfactin-like lipopeptide $[\mathrm{M}+\mathrm{Na}]^{+}$molecular adduct ion product of mass $\mathrm{m} / \mathrm{z} 1120.8$ in MALDI-TOF MS analysis.

The type strain is NRRL B-23052 $\left(=\right.$ KCTC $13429^{\mathrm{T}}=$ BGSC $3 \mathrm{~A} 28^{\mathrm{T}}$ ) and is archived within the ARS Culture Collection, the Korean Collection for Type Cultures and the Bacillus Genetic Stock Center. Strains form distinct monophyletic clusters from other $B$. subtilis subspecies in concatenated gene sequence phylogenies.

\section{ACKNOWLEDGEMENTS}

We gratefully acknowledge H. N. Kline and T. Hartman for technical support. We thank C. P. Kurtzman, D. P. Labeda, K. O'Donnell and T. J. Ward for helpful comments. We thank M. Hart and E. Quesada for providing type strains of the species they described, as well as the many other individuals who deposited their strains into the ARS Culture Collection. The mention of firm names or trade products does not imply that they are endorsed or recommended by the US Department of Agriculture over other firms or similar products not mentioned.

\section{REFERENCES}

Ash, C., Farrow, J. A. E., Wallbanks, S. \& Collins, M. D. (1991). Phylogenetic heterogeneity of the genus Bacillus revealed by comparative analysis of small-subunit-ribosomal RNA sequences. Lett Appl Microbiol 13, 202-206.

Avise, J. C. (2000). Phylogeography. The History and Formation of Species. Cambridge, MA: Harvard University Press.

Bischoff, K. M., Rooney, A. P., Li, X. L., Liu, S. \& Hughes, S. R. (2006). Purification and characterization of a family 5 endoglucanase from a moderately thermophilic strain of Bacillus licheniformis. Biotechnol Lett 28, 1761-1765.
Chun, J. \& Bae, K. S. (2000). Phylogenetic analysis of Bacillus subtilis and related taxa based on partial gyrA sequences. Antonie Van Leeuwenhoek 78, 123-127.

Cohan, F. M. (2001). Bacterial species and speciation. Syst Biol 50, 513-524.

Cohan, F. M. (2002). What are bacterial species? Annu Rev Microbiol 56, 457-487.

Cohan, F. M. (2006). Towards a conceptual and operational union of bacterial systematics, ecology, and evolution. Philos Trans $R$ Soc Lond B Biol Sci 361, 1985-1996.

Cohn, F. (1872). Untersuchungen über bakterien. Beitr Biol Pflanz 1, 127-244 (in German).

Dykhuizen, D. E. \& Green, L. (1991). Recombination in Escherichia coli and the definition of biological species. J Bacteriol 173, 72577268.

Felsenstein, J. (2006). PHYLIP (phylogeny inference package) version 3.66. Distributed by the author. Department of Genome Sciences, University of Washington, Seattle, USA. http://evolution.gs.washington. edu/phylip.html

Gatson, J. W., Benz, B. F., Chandrasekaran, C., Satomi, M., Venkateswaran, K. \& Hart, M. E. (2006). Bacillus tequilensis sp. nov., isolated from a 2000-year-old Mexican shaft-tomb, is closely related to Bacillus subtilis. Int J Syst Evol Microbiol 56, 1475-1484.

Gevers, D., Cohan, F. M., Lawrence, J. G., Spratt, B. G., Coenye, T., Feil, E. J., Stackebrandt, E., Van de Peer, Y., Vandamme, P. \& other authors (2005). Re-evaluating prokaryotic species. Nat Rev Microbiol 3, 733-739.

Gordon, R. E., Haynes, W. C. \& Pang, C. H.-N. (1973). The Genus Bacillus. US Department of Agriculture Handbook no. 427. Washington, DC: Agricultural Research Service.

Hou, C. T., Labeda, D. P. \& Rooney, A. P. (2005). Evaluation of microbial strains for linoleic acid hydroxylation and reclassification of strain ALA2. Antonie Van Leeuwenhoek 88, 167-171.

Koeppel, A., Perry, E. B., Sikorski, J., Krizanc, D., Warner, A., Ward, D. M., Rooney, A. P., Brambilla, E., Connor, N. \& other authors (2008). Identifying the fundamental units of bacterial diversity: a paradigm shift to incorporate ecology into bacterial systematics. Proc Natl Acad Sci U S A 105, 2504-2509.

Kumar, S., Tamura, K. \& Nei, M. (2004). MEGA3: integrated software for Molecular Evolutionary Genetics Analysis and sequence alignment. Brief Bioinform 5, 150-163.

Kundrat, W. (1963). Zur differenzierung aerober sporenbildner (Genus Bacillus Cohn). Zentralbl F Veterinaermed Reihe B 10, 418426 (in German).

Lane, D. J. (1991). 16S/23S rRNA sequencing. In Nucleic Acid Techniques in Bacterial Systematics, pp. 115-175. Edited by E. Stackebrandt \& M. Goodfellow. Chichester: Wiley.

Marchesi, J. R., Sato, T., Weightman, A. J., Martin, T. A., Fry, J. C., Hiom, S. J., Dymock, D. \& Wade, W. G. (1998). Design and evaluation of useful bacterium-specific PCR primers that amplify genes coding for bacterial 16S rRNA. Appl Environ Microbiol 64, 795-799.

Nakamura, L. K. (1989). Taxonomic relationship of black-pigmented Bacillus subtilis strains and a proposal for Bacillus atrophaeus sp. nov. Int J Syst Bacteriol 39, 295-300.

Nakamura, L. K., Roberts, M. S. \& Cohan, F. M. (1999). Relationship of Bacillus subtilis clades associated with strains 168 and W23: a proposal for Bacillus subtilis subsp. subtilis subsp. nov. and Bacillus subtilis subsp. spizizenii subsp. nov. Int J Syst Bacteriol 49, 1211-1215.

Palmisano, M. M., Nakamura, L. K., Duncan, K. E., Istock, C. A. \& Cohan, F. M. (2001). Bacillus sonorensis sp. nov., a close relative of 
Bacillus licheniformis, isolated from soil in the Sonoran Desert, Arizona. Int J Syst Evol Microbiol 51, 1671-1679.

Perry, E. B., Krizan, D., Rooney, A. P., Sikorski, J., Nevo, E. \& Cohan, F. M. (2007). Identifying the fundamental units of diversity among Bacillus isolates from "Evolution Canyon" III. Isr J Ecol Evol 52, 543552.

Price, N. P. J., Rooney, A. P., Swezey, J. L., Perry, E. \& Cohan, F. M. (2007). Mass spectroscopic analysis of lipopeptide for Bacillus strains isolated from diverse geographical locations. FEMS Microbiol Lett 271, 83-89.

Priest, F. G., Goodfellow, M., Shute, L. A. \& Berkeley, R. C. W. (1987). Bacillus amyloliquefaciens sp. nov., nom. rev. Int J Syst Bacteriol 37, 69-71.

Roberts, M. S., Nakamura, L. K. \& Cohan, F. M. (1994). Bacillus mojavensis sp. nov., distinguishable from Bacillus subtilis by sexual isolation, divergence in DNA sequence, and differences in fatty acid composition. Int J Syst Bacteriol 44, 256-264.

Roberts, M. S., Nakamura, L. K. \& Cohan, F. M. (1996). Bacillus vallismortis sp. nov., a close relative of Bacillus subtilis, isolated from soil in Death Valley, California. Int J Syst Bacteriol 46, 470-475.

Rooney, A. P., Swezey, J. L., Wicklow, D. T. \& McAtee, M. J. (2005). Bacterial species diversity in cigarettes linked to an investigation of severe pneumonitis in U.S. Military personnel deployed in Operation Iraqi Freedom. Curr Microbiol 51, 46-52.

Ruiz-García, C., Béjar, V., Martínez-Checa, F., Llamas, I. \& Quesada, E. (2005a). Bacillus velezensis sp. nov., a surfactant-producing bacterium isolated from the river Velez in Malaga, southern Spain. Int J Syst Evol Microbiol 55, 191-195.

Ruiz-García, C., Quesada, E., Martínez-Checa, F., Llamas, I., Urdaci, M. C. \& Béjar, V. (2005b). Bacillus axarquiensis sp. nov. and Bacillus malacitensis sp. nov., isolated from river-mouth sediments in southern Spain. Int J Syst Evol Microbiol 55, 1279-1285.

Saitou, N. \& Nei, M. (1987). The neighbor-joining method: a new method for reconstructing phylogenetic trees. Mol Biol Evol 4, 406425.

Schmidt, D. D., Frommer, W., Miller, L. \& Truscheit, E. (1979). Glucosidase-inhibitoren aus Bazillen. Naturwissenschaften 66, 584585 (in German).

Stackebrandt, E., Frederiksen, W., Garrity, G. M., Grimont, P. A. D., Kämpfer, P., Maiden, M. C. J., Nesme, X., Rossello-Mora, R., Swings, J. \& other authors (2002). Report of the ad hoc committee for the re-evaluation of the species definition in bacteriology. Int $J$ Syst Evol Microbiol 52, 1043-1052.

Tamura, K. \& Nei, M. (1993). Estimation of the number of nucleotide substitutions in the control region of mitochondrial DNA in humans and chimpanzees. Mol Biol Evol 10, 512-526.

Wang, L. T., Lee, F. L., Tai, C. J., Yokota, A. \& Kuo, H. P. (2007). Reclassification of Bacillus axarquiensis Ruiz-Garcia et al. 2005 and Bacillus malacitensis Ruiz-Garcia et al. 2005 as later heterotypic synonyms of Bacillus mojavensis Roberts et al. 1994. Int J Syst Evol Microbiol 57, 1663-1667.

Wang, L. T., Lee, F. L., Tai, C. J. \& Kuo, H. P. (2008). Bacillus velezensis is a later heterotypic synonym of Bacillus amyloliquefaciens. Int J Syst Evol Microbiol 58, 671-675.

Xia, X. \& Xie, Z. (2001). DAMBE: data analysis in molecular biology and evolution. J Hered 92, 371-373.

Zwickl, D. J. (2006). Genetic algorithm approaches for the phylogenetic analysis of large biological sequence datasets under the maximum likelihood criterion. The University of Texas at Austin. www.bio.utexas.edu/faculty/antisense/garli/Garli.html 